PUBLIPRENEUR POLIMEDIA: JURNAL ILMIAH

JURUSAN PENERBITAN POLITEKNIK NEGERI MEDIA KREATIF

Vol. 5, No. 1, June 2017

Submitted: 10 April 2017

- Revised: 14 May 2017

Accepted: 30 June 2017

\title{
STUDY PENDIDIKAN KECAKAPAN HIDUP DALAM PENDIDIKAN KARAKTER UNTUK MENGEMBANGKAN SUMBER DAYA MANUSIA DIBIDANG INDUSTRI KREATIF DI INDONESIA
}

\author{
Purnomo Ananto \\ Politeknik Negeri Media Kreatif, Jl. Srengseng Sawah, Jagakarsa, Jakarta Selatan-Indonesia \\ purnomo.ananto@polimedia.ac.id
}

\begin{abstract}
ABSTRAK
Fokus utama studi ini adalah menyajikan hasil rekonstruksi pemikiran penulis tentang pendekatan Pendidikan Kecakapan Hidup (Life Skills Education Approach) dalam Pendidikan Kewarganegaraan untuk Mengembangkan Sumberdaya Manusia Industri Kreatif di Indonesia. Hal ini didasarkan pada permasalahan utama yang ada yatitu adanya kesenjangan antara apa yang nyata ada, dengan kerangka konseptual yang ada (Das Sein dan Das Solen). Dalam konteks penelitian ini, kenyataan yang diungkapkan adalah permasalahan yang dihadapi oleh masyarakat Indonesia kontemporer yaitu globalisasi dan minimnya lapangan kerja. Penelitian ini menggunakan pendekatan kualitatif guna merekonstruksi pemikiran (Konstruktivisme) pendidikan kecakapan hidup dan pendidikan karakter dalam pendidikan kewarganegaraan, dengan pendekatan fenomenologis. Peneliti mengandalkan sebanyak mungkin pandangan responden yang digali secara mendalam untuk mengeksplorasi dan menemukan rekonstruksi pemikiran yang tepat. Data dikumpulkan melalui: (1) Studi literatur; (2) wawancara mendalam dari pelaku atau praktisi dan dari penerima mata kuliah, serta pelaku industri kreatif; (3) observasi lingkungan penelitian dan perilaku responden, data kemudian diolah melalui proses reduksi, analisis dan penyajian secara kualitatif. Simpulan penelitian ini antara lain adalah: (1) Transmisi nilai kewarganegaraan atau sistem sosial dalam institusi pendidikan dilakukan oleh pendidikan kewarganegaraan. Transmisi tersebut meliputi pendidikan karakter dan kecakapan berwarganegara. Pengetahuan tersebut merupakan pengetahuan yang secara holistik membingkai kemampuan seorang warganegara dalam berkontribusi terhadap sistem sosial di negaranya; (2) Sebagai bingkai yang holistik dalam membentuk kemampuan seorang warganegara dalam berkontribusi terhadap sistem sosialnya, pendidikan kewarganegaraan harus mampu membentuk karakter dan kecakapan hidup yang dibutuhkan dalam pengembangan sumber daya manusia; (3) Pendidikan Kecakapan hidup (Soft Skills) dalam Pendidikan kewarganegaraan yang merupakan fondasi dasar bagi pembentukan karakter bangsa yang cerdas, baik dan kreatif adalah, merupakan bagian yang sangat penting digunakan sebagai pendekatan pembelajaran pendidikan kewarganegaraan, agar dapat menghasilkan sumber daya manusia yang mampu beradaptasi dengan tuntutan perubahan di era industri kreatif ini. Berdasarkan simpulan hasil penelitian ini nampaknya diperlukan komitmen dari komunitas ilmiah pendidikan kewarganegaraan di Indonesia dalam upayanya menjawab tantangan globalisasi memerlukan pengembangan metode pembelajaran yang sesuai dengan konteks globalisasi. Metode pembelajaran kedepan harus mulai lebih banyak melibatkan peserta didik secara aktif dan aplikatif, antara lain melalui pendekatan Pendidikan Kecakapan Hidup.
\end{abstract}

KATA KUNCI : Pendidikan Kecakapan Hidup, Pendidikan Karakter, Sumber Daya Manusia, dan Industri Kreatif. 


\title{
STUDY PENDIDIKAN KECAKAPAN HIDUP DALAM PENDIDIKAN KARAKTER UNTUK MENGEMBANGKAN SUMBER DAYA MANUSIA DIBIDANG INDUSTRI KREATIF DI INDONESIA
}

\begin{abstract}
ABSTRAK
Fokus utama studi ini adalah menyajikan hasil rekonstruksi pemikiran penulis tentang pendekatan Pendidikan Kecakapan Hidup (Life Skills Education Approach) dalam Pendidikan Kewarganegaraan untuk Mengembangkan Sumberdaya Manusia Industri Kreatif di Indonesia. Hal ini didasarkan pada permasalahan utama yang ada yatitu adanya kesenjangan antara apa yang nyata ada, dengan kerangka konseptual yang ada (Das Sein dan Das Solen). Dalam konteks penelitian ini, kenyataan yang diungkapkan adalah permasalahan yang dihadapi oleh masyarakat Indonesia kontemporer yaitu globalisasi dan minimnya lapangan kerja. Penelitian ini menggunakan pendekatan kualitatif guna merekonstruksi pemikiran (Konstruktivisme) pendidikan kecakapan hidup dan pendidikan karakter dalam pendidikan kewarganegaraan, dengan pendekatan fenomenologis. Peneliti mengandalkan sebanyak mungkin pandangan responden yang digali secara mendalam untuk mengeksplorasi dan menemukan rekonstruksi pemikiran yang tepat. Data dikumpulkan melalui: (1) Studi literatur; (2) wawancara mendalam dari pelaku atau praktisi dan dari penerima mata kuliah, serta pelaku industri kreatif; (3) observasi lingkungan penelitian dan perilaku responden, data kemudian diolah melalui proses reduksi, analisis dan penyajian secara kualitatif. Simpulan penelitian ini antara lain adalah: (1) Transmisi nilai kewarganegaraan atau sistem sosial dalam institusi pendidikan dilakukan oleh pendidikan kewarganegaraan. Transmisi tersebut meliputi pendidikan karakter dan kecakapan berwarganegara. Pengetahuan tersebut merupakan pengetahuan yang secara holistik membingkai kemampuan seorang warganegara dalam berkontribusi terhadap sistem sosial di negaranya; (2) Sebagai bingkai yang holistik dalam membentuk kemampuan seorang warganegara dalam berkontribusi terhadap sistem sosialnya, pendidikan kewarganegaraan harus mampu membentuk karakter dan kecakapan hidup yang dibutuhkan dalam pengembangan sumber daya manusia; (3) Pendidikan Kecakapan hidup (Soft Skills) dalam Pendidikan kewarganegaraan yang merupakan fondasi dasar bagi pembentukan karakter bangsa yang cerdas, baik dan kreatif adalah, merupakan bagian yang sangat penting digunakan sebagai pendekatan pembelajaran pendidikan kewarganegaraan, agar dapat menghasilkan sumber daya manusia yang mampu beradaptasi dengan tuntutan perubahan di era industri kreatif ini. Berdasarkan simpulan hasil penelitian ini nampaknya diperlukan komitmen dari komunitas ilmiah pendidikan kewarganegaraan di Indonesia dalam upayanya menjawab tantangan globalisasi memerlukan pengembangan metode pembelajaran yang sesuai dengan konteks globalisasi. Metode pembelajaran kedepan harus mulai lebih banyak melibatkan peserta didik secara aktif dan aplikatif, antara lain melalui pendekatan Pendidikan Kecakapan Hidup.
\end{abstract}

KATA KUNCI : Pendidikan Kecakapan Hidup, Pendidikan Karakter, Sumber Daya Manusia, dan Industri Kreatif.

\section{PENDAHULUAN}

Penelitian ini secara umum bertujuan untuk menemukan dan merekonstruksi pemikiran Pendidikan Kecakapan Hidup dalam Pendidikan Karakter pada Pendidikan Kewarganegaraan untuk mengembangkan sumber daya manusia di bidang Industri Kreatif. Sedangkan secara khusus penelitian ini bertujuan untuk menemukan dan merkonstruksi sinergi antara abstraksi pemikiran pendidikan kewarganegaraan melalui pendekatan pendidikan kecakapan hidup dalam pendidikan karakter 
Publipreneur Polimedia: Jurnal Ilmiah Jurusan Penerbitan Politeknik Negeri Media Kreatif Vol. 5, No. 1, June 2017

dengan praktik pada dunia Industri kreatif sebagai alternatif permasalahan bagi minimnya ketersediaan lapangan kerja.

Sedangkan manfaat penelitian ini diharapkan dapat memberikan manfaat secara teoritis dan praktis bagi pengembangan keilmuan pendidikan kewarganegaraan. Dimana Manfaat secara teoritis adalah mampu menghasilkan prinsip-prinsip pendidikan kecakapan hidup dan pendidikan karakter yang sesuai dengan nilai-nilai kebangsaan Indonesia. Sedangkan Manfaat secara praktis, hasil penelitian ini diharapkan bermanfaat bagi pengembangan kurikulum dan pengambilan kebijakan pendidikan baik pada Direktorat Jenderal Pendidikan Tinggi (Dirjen Dikti), maupun Kementerian Pendidikan dan Kebudayaan, untuk merumuskan kurikulum Pendidikan karakter yang dalam Pendidikan Pancasila dan Kewarganegaraan (PPKn) melalui pendekatan Pendidikan Kecakapan hidup yang dapat mengantisipasi problem sosial aktual yang dihadapi masyarakat.

\section{METODE PENELITIAN}

Penelitian ini menggunakan metode kualitatif guna melakukan rekonstruksi pemikiran Pendidikan Kecakapan Hidup dalam Pendidikan Kewarganegaraan untuk mengembangkan sumber daya manusia dibidang industri kreatif, dengan pendekatan fenomenologis. Dimana peneliti mengandalkan sebanyak mungkin pandangan responden yang digali secara mendalam untuk mengeksplorasi dan menemukan rekonstruksi pemikiran Pendidikan Kecakapan hidup dalam Pendidikan Kewarganegaraan untuk mengembangkan sumber daya manusia dibidang Industri Kreatif yang tepat dan temuan bibliografis hasil dari studi literatur. Pendekatan penelitian kualitatif ini melingkupi penjelasan mengenai obyek telaah variable operasional penelitian, asumsi penelitian dan teknik pengumpulan dan analisis data penelitian.

Data dikumpulkan melalui: (1) Studi literatur; (2) Wawancara mendalam dari pelaku atau praktisi dan dari penerima mata kuliah, serta pelaku industri kreatif; dan (3) Observasi lingkungan penelitian dan perilaku responden. Data-data tersebut kemudian diolah melalui proses reduksi, analisis dan penyajian secara kualitatif. Ketiga tahapan tersebut berlangsung secara simultan.

Variable operasional dari penelitian ini adalah rekonstruksi pemikiran pendidikan kecakapan hidup pendidikan dalam karakter dan pengembangan sumber daya manusia (human capital) di bidang industry kreatif. Untuk melakukan rekonstruksi pemikiran, peneliti harus terlebih dahulu mengetahui konstruksi pemikiran sebelumnya dan mengetahui persepsi pelaksana dan penerima pemikiran sebelumnya.

Subyek penelitian yang digunakan dalam penelitian adalah Jurusan Admisitrasi Bisnis Fakultas 
Publipreneur Polimedia: Jurnal Ilmiah Jurusan Penerbitan Politeknik Negeri Media Kreatif Vol. 5, No. 1, June 2017

Ilmu Sosial dan Ilmu Politik Universitas Pasundan Bandung dan Komunitas NgaduIde (Pelaku Industri Kreatif). Alasan penelitian ini dilakukan di lokasi yang dipilih adalah karena Jurusan Admisitrasi Bisnis Fakultas Ilmu Sosial dan Ilmu Politik Universitas Pasundan Bandung memiliki keunikan dari prospeksi lulusannya.Seorang lulusan Jurusan Admisitrasi Bisnis harus memiliki kemampuan untuk bekerja dalam administrasi pemerintahan khususnya di bidang perniagaan dan juga memiliki kemampuan bisnis di sektor swasta.

Jurusan ini mengadopsi ilmu administrasi sekaligus manajemen sehingga memiliki dua prospek yang berbeda. Namun, keunikan inilah yang membedakan jurusan ini dengan jurusan lainnya dalam Fakultas Ilmu Sosial dan Ilmu Politik di Universitas Pasundan.Jurusan ini juga terbilang rajin mengadakan pelatihan-pelatihan kecakapan hidup baik secara professional maupun karitatif. Sebagai Jurusan yang dipayungi oleh Fakultas Ilmu Sosial dan Ilmu Politik, jurusan ini tentu harus memiliki pemahaman yang lebih lengkap mengenai politik dan kewarganegaraan. Kerja keras dalam jurusan ini adalah menyeimbangkan nilai-nilai ekonomi dengan nilai-nilai kewarganegaraan untuk mencapai kedua tujuan prospeksi lulusan diatas. Sehingga, peneliti mengasumsikan bahwa model yang sama dapat diterapkan di tempat lain.

Kemudian, komunitas NgaduIde merupakan komunitas industri kreatif yang dibentuk oleh para pemuda dan mahasiswa di Kota bandung untuk saling bertukar ide Kreatif dalam usaha kreatif. Pelaku usaha kreatif dalam komunitas ini sangat bervarian, dari produksi barang hingga produksi jasa terdapat pada komunitas ini. Anggota yang tergabung dalam komunitas ini pada umumnya adalah para mahasiswa yang baru memulai beraktivitas di bidang industri kreatif. Peneliti mendapatkan kontak dengan komunitas ini berdasarkan snowball sampling atau rekomendasi dari salah seorang peserta penelitian yaitu mahasiswa Universitas Pasundan yang diwawancarai pada saat observasi di Universitas Pasundan. Komunitas ini aktif memberikan pelatihan, seminar usaha kreatif dan pembinaan terhadap para pengusahapengusaha kreatif pemula.

\section{HASIL DAN PEMBAHASAN}

Bagian pembahasan menyajikan analisis dan pembahasan integrasi temuan penelitian bibliografis dan temuan observasi yang dikemas dalam beberapa uraian yaitu; Problematika Masyarakat Indonesia, Penidikan Karakter dalam pengembangan Sumber daya manusia, Pendidikan kecakapan hidup dalam pengembangan Sumber daya manusia, Peran Pendidikan Kewarganegaraan dalam Pengambangan Sumber daya manusia dan, Industri Kreatif dan Karakter Kebangsaan.

Sebagaimana yang telah diasumsikan pada pendahuluan penelitian disertasi ini, Indonesia menghadapi kondisi Transisional yang terjadi dari dalam melalui demokratisasi 
Publipreneur Polimedia: Jurnal Ilmiah Jurusan Penerbitan Politeknik Negeri Media Kreatif Vol. 5, No. 1, June 2017

reformasi dan dari luar melalui globalisasi. Permasalahan yang dihadapi oleh masyarakat kekinian sangat beragam namun memiliki ketersalinghubungan. Permasalahan yang dihadapi oleh masyarakat dan peserta didik saat ini merupakan permasalahan khas peradaban modern yang terjadi di masyarakat yang majemuk meliputi ekonomi, politik, sosial identitas, budaya hingga sosiopsikologis.Berdasarkan temuan penelitian yang didapat dari penyelidikan bibliografis dan observasi lapangan melalui wawancara terhadap informan, peneliti mengklasifikasikan kondisi transisional yang dihadapi masyarakat di Indonesia dalam klasifikasi berikut;

Transisi demokrasi dalam agenda reformasi seperti yang telah dipaparkan pada bab pendahuluan telah mengembalikan identitas-identitas yang dulu terkubur dimasa Orde baru. Kemajemukan masyarakat di Indonesia mencuat menjadi kekayaan sekaligus ancaman. Kemajemukan tidak hanya terdapat pada kebudayaan, suku dan rasnya namun juga resepsinya terhadap perubahan. Perkembangan suatu masyarakat tidaklah berlangsung seragam dalam peradaban manusia. Indonesia mewakili contoh paling rumit dalam perkembagan masyarakat. Karena kemajemukan masyarakat dan luasnya rentang geografis Negara ini.

Pendidikan Kewarganegaraan memiliki peran yang vital dalam mentransmisikan nilai-nilai kebangsaan. Penggalian terhadap nilai-nilai
Pancasila terutama pada sila ke-3 yaitu "Persatuan Indonesia". Pendalaman dan pemahaman terhadap sila ini merupakan sentral dari upaya menanggulangi problematika politik dan demokratisasi di Indonesia. Sedangkan sila keempat dar Pancasila yang mengisyaratkan sistem demokrasi perwakilan yang berlandaskan pada musyawarah dan mufakat menjadi landasan bagi pemahaman tentang proses demokratisasi yang dicitacitakan oleh bangsa Indonesia.

Sebagai fenomena yang mendunia, globalisasi menyimpan problematika sendiri di dalamnya. Globalisasi sebagai aktifitas ekonomi juga tak hanya berbicara soal investasi, teknologi dan modal secara parsial atau terpisah namun juga secara keseluruhan menyangkut masalah pasar tenaga kerja, angkatan kerja dan kebutuhan lapangan kerja.Globalisasi membuka peluang bagi semua orang untuk bersaing dalam pasar tenaga kerja melalui kualitas yang dimiliki oleh masing-masing individu. Hal ini menempatkan sumber daya manusia yang dimiliki oleh sebuah Negara menjadi aspek yang sangat vital bagi pertumbuhan ekonomi Negara tersebut karena melalui sumber daya manusia yang berkualitas, kemakmuran dan pertumbuhan ekonomi Negara dapat tercapai.

Pasar tenaga kerja, meskipun menyediakan peluang namun jelas membutuhkan perhatian yang khusus karena secara spesifik mengandalkan kualitas dari sumber daya manusia 
Publipreneur Polimedia: Jurnal Ilmiah Jurusan Penerbitan Politeknik Negeri Media Kreatif Vol. 5, No. 1, June 2017

tersebut.Perlu diperhatikan bahwa kualitas sumber daya manusia di setiap Negara terdapat perbedaan tingkat dan jumlah. Perbedaan tersebut juga ditentukan oleh kemampuan ekonomi dari negara-negara tersebut selain sejarah peradabannya dan dinamika masyarakat yang membentuknya.

Pendidikan karakter merupakan ujung tombak dari pendidikan karena pendidikan karakter memiliki kemampuan dan kewajiban untuk membentuk karakter masyarakat. Pada pembahasan sebelumnya di bab kedua, telah disebutkan bahwa pendidikan karakter memiliki cakupan yang lebih luas dari pendidikan moral meskipun seringkali disamakan dengan pendidikan moral. Lausnya cakupan tersebut disebabkan oleh jangkauan pendidikan karakter yang tidak hanya berkutat pada transmisi nilai secara didaktis namun juga menanamkan kebiasaan perilaku.

Pendidikan karakter juga berlaku pada dua konteks sekaligus yaitu konteks makro dan konteks mikro. Konteks tersebut dibag melalui perbedaan cakupan dan konsentrasi pembelajaran. Pendidikan karakter sendiri merupakan unsur intrinsik yang cukup kompleks dalam sistem pendidikan karena harus menjadi bagian dari seluruh proses pendidikan.

Kecakapan hidup mencakup keterampilan untuk memeroleh penghasilan dan keterampilan dasar yang harus dimiliki secara personal seperti keterampilan berpikir dan berkomunikasi. Pendidikan kecakapan hidup merupakan penghubung antara konsep pendidikan karakter yang holistic dengan pendidikan kewirausahaan yang lebih bersifat praktis.Pendidikan karakter memberikan arah bagi pembagunan kecakapan hidup dan karakter kewirausahaan yang dihasilkannya.

Dalam konteks penelitian ini yang menempatkan subjek penelitian pada para pelaku pendidikan karakter dan pendidikan kecakapan hidup, penelitian ini tidak memisahkan antara klasifikasi umum dan khusus dari kecakapan hidup. Penggabungan ini dilandasi oleh pertimbangan landasan penelitan ini sebagai suatu upaya rekonstruksi pemikiran Pendidikan Kewarganegaraan dan Pengembangan Sumber Daya Manusia

Keterhubungan antara pengembangan sumber daya manusia dengan pendidikan kewarganegaraan merupakan bagian yang paling sulit untuk ditemukan dalam penelitian ini. Hal ini disebabkan oleh literatur yang seringkali terpisah atau secara tegas memisahkan teori pengembangan Sumber Daya Manusia dengan kewarganegaraan dalam dua bidang studi yang berbeda. Pengembangan Sumber Daya Manusia cenderung diterjemahkan dalam sisi ekonomi bukan pada sisi sosialnya.

Dalam konteks ekonomi, pengembangan Sumber Daya Manusia dipandang dari tingkat profit yang dihasilkan. Sedangkan dalam konteks sosial, pengembangan Sumber Daya 
Publipreneur Polimedia: Jurnal Ilmiah Jurusan Penerbitan Politeknik Negeri Media Kreatif Vol. 5, No. 1, June 2017

Manusia dipandang dari manfaat berkelanjutan yang dihasilkan. Dalam konteks sosial tersebutlah pendidikan secara umum ataupun pendidikan kewarganegaraan secara khusus berperan penting.

kewarganegaraan belum mengulas karaker kreatif dalam tataran aplikatif kehidupan sehari-hari.

\section{KESIMPULAN}

1. Pendidikan Kecakapan hidup (Soft Skills) dalam Pendidikan kewarganegaraan yang merupakan fondasi dasar bagi pembentukan karakter bangsa yang cerdas, baik dan kreatif adalah, merupakan bagian yang sangat penting digunakan sebagai pendekatan pembelajaran pendidikan kewarganegaraan, agar dapat menghasilkan sumber daya manusia yang mampu beradaptasi dengan tuntutan perubahan di era ekonomi kreatif ini.

2. Pendidikan merupakan medium integrasi sosial dalam sebuah sistem sosial. Pendidikan memiliki kemampuan untuk memasalkan pemahaman mengenai nilai-nilai yang berlaku dalam sistem sosial tersebut. Oleh karena itu sekolah ataupun perguruan tinggi berperan besar dalam memasifkan pemahaman mengenai nilai-nilai yang berlaku dalam sistem sosial dan membangun kemampuan warganegara untuk berkontribusi dalam sistem sosial negaranya.

3. Transmisi nilai Pendidikan kewarganegaraan atau sistem sosial dalam institusi pendidikan

kewarganegaraan. Transmisi

tersebut meliputi pendidikan

karakter dan kecakapan

berwarganegara. Pengetahuan

tersebut merupakan pengetahuan yang secara holistik membingkai kemampuan seorang warga negara dalam berkontribusi terhadap sistem sosial di negaranya.

4. Sebagai bingkai yang holistik dalam mebentuk kemampuan seorang warganegara dalam berkontribusi terhadap sistem sosialnya, pendidikan kewarganegaraan harus mampu membentuk karakter dan kecakapan hidup yang dibutuhkan dalam pengembangan sumber daya manusia.

5. Penelitian ini juga menemukan bahwa karakter kreatif telah muncul dalam setiap pribadi bangsa Indonesia, hal ini dapat dilihat dari perkembangan industri kreatif yang bahkan telah berkembang sebelum menjadi perhatian dunia pendidikan. Kemampuan kreatif anak bangsa dengan menciptakan industri kreatif perlu disambut baik oleh dunia pendidikan, terutama dalm pendidikan kewarganegaraan. Sambutan tersebut merupakan kepentingan bersama bangsa Indonesia dalam memanifestasikan salah satu karakter bangsa di kancah persaingan globalisasi.

6. Industri kreatif memiliki peran penting dalam upayanya memberikan kontribusi terhadap sistem sosial dengan memberikan 
Publipreneur Polimedia: Jurnal Ilmiah Jurusan Penerbitan Politeknik Negeri Media Kreatif Vol. 5, No. 1, June 2017

kemampuan warganegara untuk kembali terserap dan memberikan kontribusi positif bagi negaranya. Peluang penghasilan dari industri kreatif dapat menempatkan kembali seorang warganegra dalam sistem sosialnya dan menghidari terjadinya penyimpangan sosial dan disintegrasi sosial. Oleh karena itu, industri kreatif menjadi bagian penting dari perkembagan peluang dalam globalisasi yang perlu ditanggapi secara tepat oleh dunia pendidikan khususnya pendidikan kewarganegaraan.

\section{DAFTAR PUSTAKA}

Alma, Buchari. 2019. Kewirausahaan. Penerbit ALFABETA. Bandung

Berybe, H. 2011. Dilema Pelembagaan Pendidikan. Dalam Sindhunata, ed. Pendidikan Kegelisahan Sepanjang Zaman. Kanisius, Yogyakarta.

Becker, Gary .S. 1993. Human Capital : A Theoritical and Empirical analysis, with special reference to Education, Third Edition. Chicago. The National Bureau of Economic Research.

Bloom, Benjamin S. 1976. Human Characteristics and School Learning. New York: McGraw-hill Inc.

Budiarjo. 1992. Pengertian- Pengertian Masyarakat. Rajawali Pers. Jakarta.

Budimansyah, Dasim. 2010. Penguatan pendidikan kewarganegaraan untuk membangun karakter bangsa. Widya Aksara Press. Bandung.
Buzan. Tony. 2001. The Power of Spiritual Intellegence. New York Chichester Brisbane Toronto Singapore by John Wiley \& Sons, Inc

Cassis, Youssef and Ioanna Pepelasis Minoglou. 2005. Entrepreneurship in Theory and History. Palgrave macmillian. New York.

Checchi, Daniele. 2005. The Economics of Education: Human Capital, Family Background and Inequality. Cambridge University Press. Cambridge.

Cogan, J.J., 1999 Developing the civic society the role of civic education, Bandung; CICED

Creswell, John W, 1994 Research Design : Qualitative and Quantitative. Approaches, California, Sage Publication

Creswell. John W. 1998. Qualitative Inquiry And Research Design: Choosing Among Five Traditions. London: SAGE Publications

Creswell, John W. 2010 Edisi ke-3. Research Design Pendekatan Kualitatif, Kuantitatif, dan Mixed. Yogyakarta

Cuff, E C, W W Sharrock and D W Francis. Perspectives in Sociology, Fourth Edition. Routledge. London.

Cuff, E. C., W. W. Sharrock and D. W. Francis, Perspectives in Sociology, third edition London, Routledge, 1992. HM66 P36 1984

Davis, Kingsley and Wilbert E. Moore, "Some Principles of Stratification," in R. Bendix and S. M. Lipset, Class, 
Publipreneur Polimedia: Jurnal Ilmiah Jurusan Penerbitan Politeknik Negeri Media Kreatif Vol. 5, No. 1, June 2017

Status and Power, second edition, New York, Free Press, 1966, pp. 4753. HT 605 B4 1966

Declaire.Gottman, John. 1997. The heart of parenting: how to raise an emotionally intelligent child. New York: Simon \& Schuster.

Delors, J. 1996. Learning: The Treasure Within. Paris: UNESCO

Departemen Pendidikan Nasional, 2007. Pendidikan Kecakapan Hidup Untuk Pencegahan HIV dam Aids, Pusat Pengembangan Kualitas Jasmani, Jakarta.

Drucker, Peter F. 1996. Inovasi dan Kewiraswastaan : Praktek dan Dasar-dasar (terjemahan).

Erlangga. Jakarta.

Educational Development Instutute, The University of Queensland.

Eltis, David, Frank D. Lewis. Kenneth L. Sokoloff. 2009. Human Capital and Instittutions. Cambridge University Press. Cambridge.

Fayolle, Alain. Handbook of Research in Entrepreneurship Education, Volume 2, Contextual Perspectives. Edward Elgar Publishing Limited. Massachusets.

Friedman, Milton. 1975. A Theory of Consumption Function. New Delhi. Oxford \& IBH Publishing.co

Fukuyama, Francis. 1989. The End of History. The National Interest. Summer.

Gottman John, 1997. Kiat - kiat Membesarkan Anak yang Memiliki Kecerdasan Emosional (Edisi terjemahan : T. Hermaya), PT. Gramedia Pustaka, Jakarta.
Grabb, Edward G., Theories of Social Inequality: Classical and Contemporary Perspectives, second edition, Toronto, Holt, Rinehart and Winston, 1990. HT609 G72

H.A.R. Tilaar. 1990. Pendidikan Dalam Pembangunan Nasional Abad XXI. Balai Pustaka. Jakarta.

Husodo, S. Y., 2004. Membangun Kemandirian Pangan : Suatu Kebutuhan Bagi Indonesia, Negara Berpenduduk Banyak Dengan Potensi Pangan yang Besar, PT Tema Baru, Jakarta

Kasmir. 2006. Kewirausahaan. PT. Raja GrafindoPersada. Jakarta.

Khoiruddin Bashori. 2010. Menata Ulang Pendidikan Karakter Bangsa. Media Indonesia.com, diunduh pada tanggal 3 Mei 2010.

Kuhn, S Thomas. 1970. The Structure of Scientific Revolutions. The University of Chicago Press. Chicago.

Lickona, Thomas. 1991. Educating for character: how our schools can teach respect and responsibility. Bantam.

Lin, Nan. 2001. Structural Analysis in the Social Sciences, Social Capital A Theory of Social Structure and Action. Cambridge University Press. Cambridge.

Lleras, Miguel Palacios. 2004. Investing in Human Capital: A Capital Markets Approach to Student Funding. Cambridge University Press. Cambridge.

Magolda, Marcia Baxter. 2001. Making Their Own Way : Narratives for Transforming Higher Education to 
Publipreneur Polimedia: Jurnal Ilmiah Jurusan Penerbitan Politeknik Negeri Media Kreatif Vol. 5, No. 1, June 2017

Promote Self-Development. Stylus. Virginia

Matthew B. Miles \& A. Michael Huberman. 1992. Analisis Data Kualitatif (translator: Tjetjep Rohendi Rohidi). UI-Press, Jakarta Mayhew, Leon H. 1992. Talcott Parsons On Institution and Social Evolution: Selected writings. The University of Chicago Press. Chicago.

Mercer, Justine, Bernard Barker and Richard Bird. 2010. Human Resource Management in Education: Contexts, Themes and Impact. Routledge. London.

Morgan, D. H. J. Social Theory and the Family, London, Routledge and Kegan Paul, 1975. HQ728 M574

Nash, Robert J. 1997. Answering Virtuecrats: A Moral Conversation On Character Education Advances in Contemporary Educational Thought Series. Teachers College Press. New York.

Nasution. 2005."Teknologi Pendidikan ". Bumi Aksara. Jakarta

Nu'man Somantri 1969, Pendidikan Kewarganegaraan di Sekolah, Bandung : Badan Penerbit IKIP Bandung.

Nu'man Somantri 2001. Menggagas Pembaharuan Pendidikan IPS. Bandung : PT Remaja Rosda karya

Parsons, Talcott and Robert F. Bales, 1955. Family, Socialization and Interaction Process, Glencoe, Illinois, Free Press. HQ734 P3

Parsons, Talcott, 1967. Sociological Theory and Modern Society, New York, Free Press. HM51P37
Parsons, Talcott, 1951. The Social System, New York, Free Press. HM51 P35

Parsons, Talcott. 2005. The Social System: With a New Preface by Bryan S. Turner. Routledge. Taylor \& Francis e-Library.

Phan, Philip H, Sankaran Venkataraman and S. Ramakrishna Velamuri. 2005. Entrepreneurship In Emerging Regions around the World: Theory, Evidence and Implications. Edward Elgar Publishing.Co. Massachusets.

Poerwandari. E. Kristi 1998. Pendekatan Kualitatif dalam Penelitian Psikologi. LPSP3 Fakultas Psikologi Universitas Indonesia, Jakarta.

Ritzer, George, Sociological Theory, third edition, New York, McGraw-Hill, 1992. HM24 R4938.

Robertson, Roland. 1991. Talcott Parsons : Theorist of Modernity Theory, Culture \& Society. Sage Publications. London.

Sanjaya, Wina. 2009. Strategi Pembelajaran Berorientasi pada Standar Proses Pendidikan. Kencana Pranada Media Group. Jakarta.

Sanusi, Ahmad 1999. Model Pendidikan Kewarganegaraan Negara Menghadapi Perubahan dan Gejolak Sosial. Makalah dipresentasikan pada Conference on Civic Education for Civil Society, di Bandung 16-17 Maret 1999 
Publipreneur Polimedia: Jurnal Ilmiah Jurusan Penerbitan Politeknik Negeri Media Kreatif Vol. 5, No. 1, June 2017

Sugiyono, (2008). Metode Penelitian Kuantitatif Kualitatif dan R\&D. Alfabeta, Bandung

Suryadi, Ace. 2002. Pendidikan, Investasi SDM, Dan Pembangunan: Isu, Teori, Dan Aplikasi. Balai Pustaka. Jakarta Suryadi, Ace. 2012. Pendidikan, Investasi SDM, dan Pembangunan : Isu Teori dan Aplikasi Untuk Pembangunan Pendidikan dan Sumber Daya Manusia Indonesia. Widya Aksara Press. Bandung.

Turner, Jonathan H., The Structure of Sociological Theory, fifth edition, Belmont, Ca., Wadsworth, 1991. HM24 T84

Winataputra, Udin Saripudin., Pendidikan Kewarganegaraan Dalam Perspektif Pendidikan Untuk mencerdaskan Kehidupan Bangsa: Gagasan, Instrumentasi, dan Praksis. Widya Aksara Press. Bandung

\section{Jurnal}

Alam, GaziMahabubul. 2009. The Role of Science and Technology Education at network age population for sustainable development of Bangladesh through human resources development. Scientific Research and Essay Vol.4.

Atmanti, Hastarini Dwi. 2005. Investasi Sumber Daya Manusia Melalui Pendidikan. Jurnal Dinamika Pembangunan Vol. 2 No 1. 30-39

Beach, D. P. (1982). A Training Program to Improve Work Habits. Journal of Epsilon PiTau 8/2, 69-74
Becker, Gary S. 1962. Investment in Human Capital: A Theoritical Analysis. The Journal of Political Economy, Vol. 70, No. 5, Part 2.

Ben-Porath, Yoram. 1967. The Production of Human Capital and the Life Cycle of Earnings. The Journal of Political Economy, Vol. 75. No 4. University of Chicago Press.

Coleman, James S. 1988. Social Capital in the creation of Human Capital. The American Journal of Sociology, vol. 94, Supplement: Organizations and Institutions: Sociological and Economic Approaches to the Analysis of Social Structure.

Pramudia, Joni Rahmat. 2006. Orientasi Pendidikan: Perlunya Reorientasi Posisi Pendidik dan Peserta didik. Jurnal Pendidikan Luar Sekolah Vol.3 No.1.

Quiggin, J. (1999), 'Human capital theory and education policy in Australia', Australian Economic Review 32(2), 130-44

Schultz, Theodore W. 1960. Capital Formation By Education. The Journal of Political Economy Vol LXVIII. No. 6. University of Chicago

Schultz, Theodore W. 1961. Investment in Human Capital. The American Economic Review. American Economic Association.

\section{Disertasi}

Samsuri. 2010. Transformasi Gagasan Masyarakat Kewargaan (Civil Society) Melalui Reformasi Pendidikan Kewarganegaraan di 
Publipreneur Polimedia: Jurnal Ilmiah Jurusan Penerbitan Politeknik Negeri Media Kreatif Vol. 5, No. 1, June 2017

Indonesia. Universitas Pendidikan Indonesia. Bandung.

Sapriya, (2007), Disertasi Doktor Ilmu Kependidikan dalam Bidang IPS, dengan judul : "Perspektif Pemikiran Pakar Tentang Pendidikan Kewarganegaraan Dalam Pembangunan Karakter Bangsa", Sekolah Pasca Sarjana UPI, Bandung, 2007.

Winataputra, Udin Saripudin. 2001. Jatidiri Pendidikan Kewarganegaraan Sebagai Wahana Sistemik Pendidikan Demokrasi. Universitas Pendidikan Indonesia. Bandung

\section{Dokumen}

Kementrian Pendidikan Nasional Badan Penelitian dan Pengembangan Kurikulum. 2010. Bahan Pelatihan: Penguatan Metodologi Pembelajaran Berdasarkan Nilainilai Budaya untuk membentuk Daya Saing dan Karakter Bangsa.

Badan Penelitian Statistik. Keadaan Ketenagakerjaan 2011. Berita Resmi Statistik No. 74/11/Th. XIV, 7 November 2011

Badan Standar Nasional Pendidikan. 2010. Paradigma Pendidikan Nasional Abad XXI Versi 1.0

Departemen Pendidikan Nasional. 2003. Konsep Pendidikan Kecakapan Hidup. Direktorat pendidikan dasar dan menengah kejuruan.

Nan-Zhao, Z. 2006. Revisiting 4 Pillars of Learning. Managing Curriculum Change:

Seminar-Workshop 7-9 June 2006, PSSC, Quezon City, Philippines.
Peraturan Perundangan

Undang Undang Sistem Pendidikan Nasional. UU No.20 Tahun 2003

Undang-undang Nomor 12 Tahun 2012

Tentang Pendidikan Tinggi

Instruksi Presiden Republik Indonesia

Nomor 6 Tahun 2009 Tentang

Pengembangan Ekonomi Kreatif 